\title{
Nuevos movimientos eclesiales. Naturaleza de los carismas, cuestiones jurídicas y límites*
}

\author{
New Ecclesial Movements. The Nature of Charisms, \\ Legal Concerns and Limits
}

\section{Luis NAVARRO}

Profesor Ordinario de Derecho de la persona

Pontificia Università della Santa Croce. Facoltà di Diritto Canonico. Roma

orcid 0000-0002-9066-9239

navarro@pusc.it

Resumen: Las realidades carismáticas están llamadas a encontrar una integración adecuada en la Iglesia. Para ello es necesario respetar la naturaleza del carisma y de la Iglesia. La diversidad de movimientos eclesiales ha dado frecuentemente lugar a variadas configuraciones jurídicas, algunas unitarias y otras sectoriales, no satisfactorias, pues impiden el desarrollo adecuado del movimiento. Cualquiera que sea la configuración jurídica adoptada, en los estatutos del ente, por un lado, se deberá respetar las relaciones de justicia entre los miembros, permitir el ejercicio de sus derechos y deberes reflejo de su dignidad humana y cristiana, y los provenientes de su condición eclesial (laico, clérigo, casado, fiel de vida consagrada). Por otro, los estatutos deberán estar en consonancia con la naturaleza del carisma, ya sea éste más bien secular o típico de la vida religiosa. Se prospectan algunas vías para salvaguardar la unidad en el movimiento y para incardinar clérigos en tales movimientos.

Palabras clave: Movimientos eclesiales, Configuración jurídica, Incardinación.
Abstract: Charismatic phenomena are to be integrated properly within the Church, with respect for both the nature of the charism and of the Church herself. The variety of ecclesial movements has often led to the institution of different legal structures (either for the movement as a whole, or for separate parts of it) that may compromise its own proper development. Regardless of the particular legal structure instituted, it is fundamental that the statutes of the movement establish relationships based on justice among its members, and enable the exercise of rights and duties in light of these members' human and Christian dignity, and ecclesial status (lay, clerical, married, consecrated state). At the same time, the statutes must reflect the nature of the charism, be it secular or religious. This article discusses a number of ways to safeguard the unity of such movements and the incardination of clerics within them.

Keywords: Ecclesial Movements, Legal Structure, Incardination.

* Versión castellana de la conferencia pronunciada en Roma el 18 de enero de 2018 en la jornada titulada Carisma e istituzione in movimenti e comunità ecclesiali. 


\section{INTRODUCCIÓN}

$E$ n el coloquio que tuvo el Cardenal Ratzinger con algunos obispos, en 1999, en el marco de un seminario de estudio organizado por el Pontificio Consejo para los Laicos, el futuro Papa constataba que en los movimientos era inevitable una cierta institucionalización, y que aquello que comienza sin estructuras jurídicas acaba encontrando una posición en el derecho que le ayuda a integrarse en el conjunto de la vida de la Iglesia ${ }^{1}$. Y añadía: «únicamente debemos estar muy atentos para evitar que la institución se convierta en una armadura que termine por sofocar la vida, y hacer lo que podamos para que el elemento institucional se mantenga, por decirlo así, sencillo, de modo que no apague el Espíritu»².

En los últimos decenios la Iglesia ha debido afrontar el problema de la relación entre carisma e institución, relación que frecuentemente no es fácil a causa de la novedad carismática, que da lugar a nuevos desafíos no sólo para los Pastores, sino también para teólogos y canonistas.

Manifestación privilegiada de la relación entre carisma e institución, desde una perspectiva jurídica, es el acto de reconocimiento de una realidad agregativa atribuyéndole una configuración jurídica. La tarea es sumamente delicada porque por una parte se ha de evitar que se asfixie el carisma y por otra se ha de favorecer su inserción en la comunión de la Iglesia.

En la Carta Iuvenescit Ecclesia de la Congregación para la Doctrina de la $\mathrm{Fe}$, de 15 de mayo de 2016, se encuentran elementos que pueden ayudar a tratar de la relación entre carisma e institución en los movimientos. En la sección

1 «Vorrei dire qualcosa anche a proposito del suo accenno al fatto che anche nei movimenti comincia inevitabilmente una certa burocratizzazione o almeno istituzionalizzazione. In effetti si tratta di una evoluzione osservabile in tutta la storia a partire dal monachesimo, fenomeno che comincia come movimento privo di strutture giuridiche, ma deve poi trovare e trova delle regole e quindi anche il suo stato giuridico nella Chiesa. Lo stesso accade con i grandi movimenti del Duecento e soprattutto con il Francescanesimo che voleva essere semplicemente un risveglio del popolo di Dio e poi, quasi contro la volontà di san Francesco, dovette trovare anche forme giuridiche. Lo stesso succede anche oggi. (...) Ma anche loro cominciano a capire che una certa struttura è necessaria, che una struttura ovviamente limita in qualche modo il dinamismo iniziale, ma d'altra parte canalizza anche le forze e così consente anche un effetto più ordinato e aiuta l'integrazione nell'insieme della vita della Chiesa, della parrocchia e nella diocesi» (J. RATZINGER, Dialogo con il cardinale foseph Ratzinger, en PONTIFICIUM CONSILIUM PRO LAICIS, I movimenti ecclesiali nella sollecitudine pastorale dei vescovi, Libreria Editrice Vaticana, Città del Vaticano 2000, 228-229).

2 «dobbiamo soltanto stare molto attenti per evitare che l'istituzione diventi un'armatura che alla fine schiaccia la vita e fare il possibile perché l'elemento istituzionale resti per così dire semplice, in modo che non spenga lo Spirito» (J. RATZINGER, Dialogo con il cardinale foseph Ratzinger, cit., 229). La traducción es nuestra. 
dedicada a las Formas de reconocimiento eclesial se hacen afirmaciones importantes: por una parte, que existe diversidad de formas para el reconocimiento eclesial de las realidades de origen carismático; por otra, que para determinar la configuración más adecuada para un movimiento, habrá que tomar en consideración dos elementos que han de ser valorados en su justo equilibrio: los principios fundamentales del derecho y la naturaleza y peculiaridades de las diversas realidades carismáticas ${ }^{3}$. Con referencia a los principios fundamentales del derecho cabe indicar que en los movimientos se deben respetar tanto los elementos jurídicos propios de la naturaleza de la Iglesia y de las agregaciones de fieles suscitadas por los carismas, como aquellas exigencias de justicia presentes en las relaciones interpersonales entre los miembros de tales realidades. Hay que afirmar sin embargo que el proceso de discernimiento de la configuración jurídica se refiere a la realidad agregativa concreta en su peculiaridad: cada una es única, y por consiguiente diversa de las demás.

Para la tarea, que no es sencilla, de encontrar la configuración jurídica más adecuada, la Carta recién citada, en su número 23, ofrece algunas indicaciones:

«Desde el punto de vista de la relación entre los diversos dones jerárquicos y carismáticos es necesario respetar dos criterios fundamentales que deben ser considerados inseparablemente: a) el respeto por las características carismáticas de cada uno de los grupos eclesiales, evitando forzamientos jurídicos que mortifiquen la novedad de la cual la experiencia específica es portadora. De este modo se evitará que los diversos carismas puedan considerarse como recursos no diferenciados dentro de la Iglesia. b) El respeto del régimen eclesial fundamental, favoreciendo la promoción activa de los dones carismáticos en la vida de la Iglesia universal y particular, evitando que la realidad carismática se conciba paralelamente a la vida de la Iglesia y no en referencia ordenada a los dones jerárquicos».

Al determinar la configuración jurídica de los movimientos se ha de huir dos riesgos posibles: de un lado, no respetar el carisma del movimiento, introduciéndolo en esquemas rígidos que lo sofoquen y lo limiten. La tentación sería prescindir del carisma: como si se dijese "lo que no entra en este esquema, no existe”. El otro peligro consiste en separar el carisma de la Iglesia, es

3 «Dichas formas deberán considerarse atentamente, evitando supuestos que no tengan en adecuada consideración tanto los principios fundamentales del derecho como la naturaleza y las peculiaridades de las diversas realidades carismáticas» (CONGREGACIÓN PARA LA DOCTRINA DE LA FE, Carta Iuvenescit Ecclesia, 15 mayo 2016, n. 23). 
decir, de su correcta inserción en ella: se convertiría entonces en una especie de bala perdida que corre el riesgo de provocar graves daños. Se ha de respetar la peculiaridad del carisma, garantizando al mismo tiempo que crezca en la Iglesia y al servicio de la Iglesia misma. Un movimiento no es una realidad paralela, al margen de la Iglesia universal y particular ${ }^{4}$.

La relación entre carisma e institución en los movimientos no ha encontrado siempre soluciones felices en lo relativo a la unidad del movimiento y a la posición de sus clérigos ${ }^{5}$. Los puntos críticos fundamentales han sido, por un lado, no haber hallado una solución unitaria para todo el movimiento, debiendo recurrir a soluciones parciales: cada sector recibe un reconocimiento separado. Esto provoca problemas para la unidad de gobierno del movimiento, porque se trata de entes jurídicamente diversos. Por otro lado, se plantea el problema de la incardinación de los clérigos en el movimiento. Si la configuración jurídica conferida al movimiento no permite la incardinación, se ha recurrido a convenios entre movimiento y diócesis de incardinación. El sacerdote del movimiento incardinado en la diócesis puede no sentirse miembro del presbiterio diocesano, y en cambio vive siempre y dondequiera que esté como sacerdote del movimiento, a cuyo servicio ejerce el ministerio. Estas soluciones conllevan riesgos. El problema de fondo es cómo garantizar siempre la unidad de la nueva realidad eclesial y cómo encontrar una posición adecuada para los clérigos del movimiento ${ }^{6}$.

${ }^{4}$ En toda realidad eclesial debe estar viva la conciencia de formar parte de la Iglesia, y en consecuencia, de estar al servicio de la unidad. Cada don del Espíritu, como son los movimientos eclesiales, lo es para la Iglesia, y en consecuencia los miembros de los movimientos deben necesariamente procurar la comunión en la Iglesia con los Pastores, sucesores de los Apóstoles. Cfr. J. RATZINGER, Dialogo con il cardinale foseph Ratzinger, cit., 32-235, e IDEM, I Movimenti ecclesiali e la loro collocazione teologica, en PONTIFICIUM CONSILIUM PRo LAICIS, I movimenti nella Chiesa. Atti del Congresso mondiale dei movimenti ecclesiali, Roma, 27-29 maggio 1998, Libreria Editrice Vaticana, Città del Vaticano 1999, en particular la parte III. Distinzioni e criteri, 47-51.

5 Tanto J. Beyer como G. Ghirlanda subrayaron ya en los años 80 y 90 del siglo pasado la presencia de estos problemas. Cfr. J. BEYER, I movimenti ecclesiali, Vita consacrata 23 (1987) 143-156, IDEM, Il movimento ecclesiale: questioni attuali, Vita consacrata 26 (1990) 483-494; G. GHIRLANDA, Questioni irrisolte sulle associazioni dei fedeli, Ephemerides Iuris canonici 49 (1993) 73-102. Me he ocupado del tema, con soluciones en parte distintas de las propuestas por los autores citados, en Canonical dimensions of the new charisms and ecclesial movements, Philippine Canonical Forum 4 (2002) 37-74.

${ }^{6}$ Otro problema es la configuración de la entrega total a Dios en los movimientos: ¿estamos ante una consagración verdadera por la que el fiel se convierte en fiel de vida consagrada? Sobre este tema vid. L. Navarro, Aspectos canónicos de la consagración, en M. Blanco - B. Castillo J. A. Fuentes - M. SánCHez Lasheras (coords.), Ius et iura. Escritos de Derecho Eclesiástico y de Derecho Canónico en honor del profesor fuan Fornés, Comares, Granada 2010, 807-828 y la bibliografía allí citada. Más recientemente se ha ocupado del tema, A. GANCI, La questione della consacrazione dei fedeli nei Movimenti Ecclesiali. Stato attuale e prospettive future, Roma 2018. 
En las páginas que siguen, presentaré algunas observaciones sobre estas cuestiones e intentaré dar algunas respuestas a los citados problemas. Pero primero, analizaré las configuraciones jurídicas usadas hasta ahora para los movimientos, indicando los límites de la praxis actual. A continuación, indicaré algunos puntos que puedan contribuir a una configuración jurídica más satisfactoria. Por último, trataré brevemente de algunas cuestiones relativas a la incardinación de los clérigos en los movimientos.

Conviene, sin embargo, mostrar antes dos pistas que ofrece la carta Iuvenescit Ecclesia para examinar las diversas cuestiones jurídicas: el énfasis sobre la peculiaridad del carisma y el respeto de los principios fundamentales del derecho. No se trata de analizar qué sitio le corresponde en la Iglesia a un movimiento, sino de hacerse cargo y examinar un carisma en su vida eclesial concreta, identificando las exigencias jurídicas que se derivan de ello. Solo así se pueden encontrar las debidas conciliaciones, que son adecuaciones entre la novedad carismática y su colocación dentro de la Iglesia y a su servicio. Cuando se trata de la configuración jurídica de un movimiento se ha de ser siempre consciente de que en su origen hay siempre un carisma y por tanto esta realidad eclesial no es nunca fruto de la voluntad del fiel o de la misma autoridad, sino de una iniciativa que viene de lo Alto, que ha de ser no sólo respetada sino secundada. La cercanía con cualquier realidad carismática exige una especial sensibilidad hacia aquello que viene del Espíritu?

El respeto de los principios fundamentales del derecho, señalado también en la Carta Iuvenescit Ecclesia, resulta de importancia vital en dos ámbitos distintos, aunque relacionados entre sí: todo don del Espíritu Santo está esencialmente en armonía con la Iglesia y con su estructura, con la Jerarquía y sus funciones, y por tal motivo no puede entrar en conflicto con ella. Y además, cualquier carisma que dé vida a un movimiento estará siempre en armonía con todo aquello que procede de la dignidad cristiana y humana del fiel, que constituye el fundamento de los derechos y deberes del fiel en la Iglesia. Si en un movi-

\footnotetext{
${ }^{7}$ Los movimientos no son realidades que surgen desde abajo, de la decisión de los fieles de unir sus fuerzas para conseguir un fin. La iniciativa proviene de lo Alto: es el Espíritu el que dona el carisma. «Si el Señor nos da nuevos dones, debemos estar agradecidos, aunque a veces sean incómodos. $\mathrm{Y}$ es algo hermoso que, sin iniciativa de la jerarquía, con una iniciativa de la base, como se dice, pero también con una iniciativa realmente de lo Alto, es decir, como don del Espíritu Santo, nazcan nuevas formas de vida en la Iglesia, como, por otra parte, han nacido en todos los siglos» (BENEDICTO XVI, Discurso en el encuentro con los párrocos y el clero de la diócesis de Roma, 22 febrero 2007, in http://w2.vatican.va/content/benedict-xvi/es/speeches/2007/february/ documents/ hf_ben-xvi_spe_20070222_clergy-rome.html).
} 
miento existieran violaciones de los derechos individuales o colectivos, podríamos estar seguros de que tales abusos no provienen de un carisma verdadero o de que el carisma no ha sido respetado en su integridad.

\section{CONFIGURACIONES JURÍDiCAS}

¿Qué configuraciones han sido aplicadas a los movimientos? En la carta Iuvenescit Ecclesia, en la nota 116, se enumeran las diversas posibilidades empleadas hasta ahora, y que están previstas en la legislación vigente de la Igle$\operatorname{sia}^{8}$. En ciertos casos la figura jurídica usada ha permitido dar una configuración unitaria a todo el movimiento. Otras veces, la solución aplicada mira tan sólo a un sector, y en consecuencia surge el problema de cuál es su colocación en el seno del movimiento y cómo se coordina con las otras partes.

Habitualmente se ha empleado la categoría de asociación de fieles y casi siempre privada ${ }^{9}$. Se trata de la solución jurídica más flexible, que reconoce amplio espacio a la autonomía del ente, permite dar notoriedad a la naturaleza eclesial de un ente, facilitando su plena inclusión en la estructura eclesial como asociación diocesana, nacional o internacional. Hay que señalar que en esta configuración la voluntad de los fieles tiene un papel fun-

\footnotetext{
${ }^{8} \ll$ La forma jurídica más simple para el reconocimiento de las realidades eclesiales de naturaleza carismática es actualmente la de Asociación privada de fieles (cfr. Código de Derecho Canónico, cann. 321-326; Código de los Cánones de las Iglesias Orientales, cann. 573, \$2-583). Sin embargo, es bueno considerar atentamente también las otras formas jurídicas con sus propias características específicas, como por ejemplo las Asociaciones públicas de fieles (cfr. Código de Derecho Canónico, cann. 312-320; Código de los Cánones de las Iglesias Orientales, cann. 573, \$2-583), las Asociaciones de fieles "clericales" (cfr. Código de Derecho Canónico, can. 302), los Institutos de vida consagrada (cfr. Código de Derecho Canónico, cann. 573-730; Código de los Cánones de las Iglesias Orientales, cann. 410-571), las Sociedades de Vida apostólica (cfr. Código de Derecho Canónico, cann. 531-746; Código de los Cánones de las Iglesias Orientales, can. 572) y las Prelaturas personales (cfr. Código de Derecho Canónico, cann. 294-297)» (CONGREgaCión PARA la DoctRINA DE la FE, Carta Iuvenescit Ecclesia, cit., nota 116).

9 Sobre las asociaciones de fieles y la normativa canónica, cfr. Ll. MarTínEZ SisTACH, Las asociaciones de fieles, Thomson Reuters Aranzadi, Cizur Menor (Navarra) 2016; J. Amos, Associations of the Christian Faithful in the 1983 Code of Canon Law: a canonical Analysis and Evaluation, Washington 1986; W. Schulz, Der neue Codex und die kirchliche Vereine, Bonifatius, Paderborn 1986; W. Aymans, Kirchliche Vereinigungen, F. Schöningh, Paderborn 1988; L. NAVARRO, Diritto di associazione e associazioni di fedeli, Giuffrè, Milano 1991; Gruppo Italiano Docenti Di DiritTo CaNONICO (a cura di), Fedeli, associazioni, movimenti, Glossa, Milano 2002, 127-265; V. MARANO, Il fenomeno associativo nell'ordinamento ecclesiale, Giuffrè, Milano 2003; G. RivetTI, Il fenomeno associativo nell'ordinamento della Chiesa tra libertà e autorità, Giuffrè, Milano 2008; J. A. FuENTES (ed.), Las asociaciones de fieles. Aspectos canónicos y civiles, Eunsa, Pamplona 2011; y Esperienze associative nella Chiesa. Aspetti canonistici, civili e fiscali, Libreria Editrice Vaticana, Città del Vaticano 2014.
} 
damental, tanto en la creación del ente como en su desarrollo y en su extinción ${ }^{10}$. Desde el punto de vista de su composición, se atribuye al ente una gran libertad: fieles de todo tipo pueden ser miembros de las asociaciones privadas (hombres y mujeres, clérigos, laicos, consagrados, e incluso no católicos $\left.{ }^{11}\right)$.

Menos frecuente ha sido el recurso a la figura de la asociación pública ${ }^{12}$. Ésta garantiza, como en el caso de las asociaciones privadas, la unidad del movimiento. Pero sitúa al ente en una dependencia más estrecha respecto a la autoridad eclesiástica (la alta dirección) y determina que, en cuanto persona jurídica pública, los bienes del movimiento sean bienes eclesiásticos, sometidos por tanto a los controles previstos en el derecho canónico. También a estos entes puede pertenecer cualquier tipo de fiel. Tal vez las dificultades para llevar a cabo las amplias funciones de vigilancia y de control atribuidas a la autoridad eclesiástica han condicionado de hecho el empleo de esta configuración ${ }^{13}$. Hay que subrayar que con frecuencia las curias diocesanas, la Conferencia episcopal o incluso la Curia romana no están dotadas de recursos humanos y materiales suficientes para desarrollar estas funciones.

Los límites del cuadro asociativo diseñado por el CIC 1983 afectan, por una parte, a la voluntad de algunos movimientos de tener clérigos incardinados directamente en el movimiento y, por otra parte, al deseo de tener vida consagrada reconocida como tal por la Iglesia, dentro del mismo movimiento. En efecto, no está previsto en la normativa latina vigente que los clérigos se incardinen en las asociaciones, y éstas son distintas de los Institutos religiosos y seculares, que son las dos formas colectivas de vida consagrada ${ }^{14}$.

Otras soluciones que se indican en la citada nota de la carta Iuvenescit Ecclesia suscitan ciertas perplejidades porque resultan soluciones parciales dentro del movimiento y revelan una tipología carismática específica.

${ }^{10}$ Cfr. can. $299 \$ 1$.

${ }^{11}$ Cfr. G. FeLICIANI, La partecipazione di altri credenti alla vita delle associazioni cattoliche, en PONTIFICIUM CONSILIUM PRO LAICIS, Ecumenismo e dialogo interreligioso: il contributo dei fedeli laici, Città del Vaticano 2002, 163-168; y L. NAVARro, «Asociación de fieles», en J. OTADUY - A. Viana J. Sedano (eds.), Diccionario General de Derecho Canónico, I, Thomson Reuters Aranzadi, Cizur Menor (Navarra) 2012, 524-525 (en adelante, DGDC).

12 Por ejemplo, son asociaciones públicas la Comunidad del Emmanuel y la Comunidad de San Egidio.

13 Las funciones de vigilancia y control que lleva a cabo la autoridad eclesiástica constituyen la alta dirección prevista por el CIC.

${ }^{14}$ Cfr. can. $298 \$ 1$. 
a) La figura de la asociación clerical del can. 302 afecta únicamente a los clérigos del movimiento, no a los laicos, ni a los religiosos o religiosas ${ }^{15}$. Se trata de una asociación solamente de clérigos, muy ligada al ejercicio del ministerio sagrado. A partir del 11 de enero de 2008, cuando el papa Benedicto XVI concedió a la Congregación para el clero el privilegio de dar la facultad de incardinar a algunas asociaciones clericales ${ }^{16}$, esta solución ha sido usada para clérigos de dos movimientos ${ }^{17}$ : dentro del movimiento se crea una asociación clerical. Para evitar que el movimiento se divida y que cada uno de los entes discurra por su cuenta, se deben establecer las modalidades de coordinación entre ellos.

b) La figura de los Institutos de vida consagrada (institutos religiosos e institutos seculares) ha sido aplicada para algunos sectores de ciertos movimientos ${ }^{18}$. El carisma del movimiento lleva a algunos miembros a vivir un estilo de vida específico dentro de la Iglesia, que corresponde a una vocación que no todos pueden compartir. El estilo de vida propio de los institutos de vida consagrada tiene características propias, determinadas por la normativa canónica. En consecuencia, sería una configuración parcial, aplicable sólo a un sector del movimiento ${ }^{19}$.

15 En el proceso de revisión del CIC de 1917, junto al actual canon 302 se pensó en una normativa más compleja que preveía tanto la incardinación de clérigos como la presencia de laicos en las asociaciones clericales. Pero se acabó por abandonar esas previsiones y se mantuvo sólo el canon 302. Vid. L. Navarro, Sub c. 302, en Comentario exegético al Código de Derecho Canónico, II, Eunsa, Pamplona 2002, 443-445; y R. RODRÍGUEZ-OCAÑA, Las asociaciones de clérigos en la Iglesia, Eunsa, Pamplona 1989, 247-254 y 257-269.

16 «Talune Associazioni clericali sentono l'esigenza di poter incardinare alcuni o tutti i membri, a seconda delle situazioni, per assicurare la stabilità del loro carisma e l'efficacia operativa delle loro strutture" (...) "Per rispondere a tale legittima esigenza, l'11 gennaio 2008, il Santo Padre Benedetto XVI ha concesso alla Congregazione per il Clero il privilegio di poter concedere ad alcune associazioni clericali la facoltà di incardinare i membri che ne fanno richiesta» (Annuario Pontificio, 2018, Libreria Editrice Vaticana, 1850-1851).

${ }^{17}$ La asociación clerical "Opera di Gesù Sommo Sacerdote (Opus J.S.S.)", con estatutos aprobados el 22 de mayo de 2002, está unida al movimiento Pro Deo et fratribus-Famiglia di Maria, cfr. Annuario Pontificio, 2018, cit., 1671. Recientemente, el 15 de agosto de 2017, la Congregación para el clero ha erigido la Asociación clerical de la Comunidad del Emmanuel para los clérigos de la Comunidad del Emmanuel. En la misma fecha ha aprobado su Estatuto. Hay otras asociaciones clericales con facultad de incardinar clérigos, pero no son parte de un movimiento. Son las siguientes: la Communauté Saint Martin, la Société Jean-Marie Vianney y la Hermandad de Sacerdotes Operarios Diocesanos del Corazón de Jesús (Sodalitas Sacerdotum Operariorum Dioecesanorum Cordis Iesu). Cfr. Annuario Pontificio, 2018, cit., 1671.

18 Cfr. cann. 573-730. Sobre la vida consagrada, cfr. V. DE PAOLIS - V. MosCA, La vita consacrata nella Chiesa, Marcianum Press, Venezia 2010; y T. RinCóN-PÉREZ, La vida consagrada en la Iglesia latina: estatuto teológico-canónico, Eunsa, Pamplona 2001.

19 En estas realidades se plantea el problema de si las personas casadas pueden pertenecer a título pleno. De hecho, según la ex. ap. Vita Consecrata, los fieles casados no pueden formar parte de estos institutos. Cfr. SAN JuAN Pablo II, ex. ap. Vita Consecrata, 25 marzo 1996, n. 62. 
c) Otra configuración parcial sería la de Sociedad de Vida Apostólica, en parte próxima a la vida consagrada aunque no idéntica; en cualquier caso, está siempre caracterizada por la vida en común ${ }^{20}$. Pero no todos los miembros de los movimientos hacen vida en común.

d) Por último, la configuración como Prelatura personal, adoptada hasta ahora sólo para el Opus Dei, tendría la ventaja de ser una solución unitaria en la que cabrían juntos clérigos y laicos, hombres y mujeres, algunos viviendo el celibato por el Reino de los cielos y otros casados. Los clérigos estarían también incardinados en la Prelatura constituyendo un presbiterio. La peculiaridad de esta configuración es que si un movimiento se convierte en Prelatura personal ya no sería un ente agregativo sino un ente jerárquico, como el mismo concepto de Prelatura y la misión pastoral inherente a ellas indican (hay siempre una mutua interrelación estructural entre el sacerdocio común y el sacerdocio ministerial) ${ }^{21}$. No son los fieles los que constituyen un ente jerárquico, sino que es la autoridad la que constituye el ente, le da los estatutos, coloca como cabeza a un Pastor, un Prelado, constituye un presbiterio y atribuye un pueblo y una misión pastoral. El criterio de delimitación sería personal y no territorial (el habitual para los entes jerárquicos). En el caso concreto del Opus Dei existe un ente jerárquico unido a un carisma que empuja al desarrollo de una misión pastoral.

\section{LÍMITES DE LA PRAXIS ACTUAL}

Como consecuencia de las configuraciones insuficientes y parciales, la doctrina ha resaltado los peligros para la unidad del movimiento, y el riesgo de atomización y de multiplicación de autoridades eclesiásticas competentes. Un

${ }^{20}$ Cfr. cann. 731-746. Sobre el tema, vid. A. D'AURIA, Le società di vita apostolica, en GRUPPO ITALiano Docenti Di DiritTo Canonico (a cura di), La vita consacrata nella Chiesa, Glossa, Milano 2006, 169-194.

21 A pesar de algunas incertezas en la doctrina, motivadas sobre todo por la colocación sistemática de las prelaturas personales en el CIC 1983, algunos estudios más detallados subrayan la distinción entre las asociaciones y las prelaturas personales, indicando que se trata de entes de naturaleza claramente diversa. A. STANKIEWICZ, Le prelature personali e i fenomeni associativi, en S. GHERRO (a cura di), Le prelature personali nella normativa e nella vita della Chiesa, Venezia-Scuola Grande di San Rocco, 25 e 26 giugno 2001, CEDAM, Padova 2002, 137-163. Sobre el Opus Dei como prelatura personal, cfr. SAN JUAN PABLO II, Const. ap. Ut sit, 28 noviembre 1982, A. DE FuenMayor - V. GÓmez Iglesias - J. L. Illanes, El itinerario jurídico del Opus Dei: historia y defensa de un carisma, Eunsa, Pamplona 1989. Vid. también sobre el tema, Carta del Card. Baggio a mons. Álvaro del Portillo 17 enero 1983, sobre las prelaturas personales, Studia et Documenta 5 (2011) 379-380 (con nota de J. L. ILlanes, ibid., 369-378). 
carisma unitario daría vida a entes diversos, separados entre sí, con una comunicación interna tal vez bastante difícil. Incluso en los casos en los que permanecen todos unidos en un ente general, se asiste a la paradoja de tener un gobierno del movimiento, frecuentemente de naturaleza privada (una asociación privada de fieles), encargado de ejercitar su función, también en relación a entes de naturaleza pública. No resulta por tanto razonable que un ente privado pueda gobernar un ente público pues será fácil que surjan tensiones. Hace todavía más difícil la unidad el hecho de que diversos dicasterios de la Curia romana serían competentes de modo simultáneo (el Dicasterio para los Laicos, la Familia y la Vida, la Congregación para los Institutos de vida consagrada y Sociedades de vida apostólica y la Congregación del Clero $^{22}$ ). Para la resolución de problemas de coordinación se deberían crear comisiones interdicasteriales ${ }^{23}$.

\section{UNA DIFICULTAD PARA UNA CONFIGURACIÓN UNITARIA:}

\section{LA GRAN DIVERSIDAD DE MOVIMIENTOS}

¿Qué camino tomar, qué vía seguir para dar una configuración adecuada al movimiento? Debemos partir de un dato cierto: hay una gran variedad de carismas y de modos de encarnarlos en la práctica. Además, el carisma no es un don que "brota" un día con todos sus elementos perfectamente identificados. Algunos movimientos y comunidades han nacido y se han desarrollado a lo largo de decenios, otros son mucho más jóvenes, otros han sufrido parones, algunos se han recuperado, otros no. Se da también una evolución en la percepción del carisma y de sus frutos. Incluso, como demuestra la historia, un único carisma puede dar lugar a diversas realidades eclesiales, o sólo a una.

Por lo demás, desde el punto de vista del compromiso de los fieles, los movimientos no son iguales. Algunos necesitan que algunos fieles se pongan al servicio del carisma de modo completo: viven para dar vida a aquel carisma, encarnarlo, para llevarlo a la práctica y eso supone dedicarse totalmente a Dios, abandonando su casa, su familia, y a veces incluso sus ocupaciones habituales (trabajo, estudios, aficiones, ambientes culturales, etc.) y hasta las rela-

22 Cfr. Francisco, Estatuto del Dicasterio para los Laicos, la Familia y la Vida, 10 de abril de 2018, art. $7 \$ 2$ (https://press.vatican.va/content/salastampa/es/bollettino/pubblico/2018/05/08/dic. html), y SAN Juan PABlo II, Const. ap. Pastor Bonus, 28 de junio de 1988, art. $95 \$ 1$ y art. 106 $\$ 2$. Cfr. M. Delgado, Un nuovo dicastero per i fedeli laici, la famiglia e la vita, Ius Ecclesiae 28 (2016) 700-715.

23 San Juan Pablo II, Const. ap. Pastor Bonus, cit., art. 21. 
ciones humanas que hasta aquel momento habían caracterizado su existencia: cambian de ciudad, de país, reduciendo drásticamente sus relaciones con amigos, colegas y parientes. En otros casos, seguir un carisma resulta menos comprometido, es más soft: basta con acudir a algunas reuniones formativas y de oración, a algunas convivencias, leer algunos escritos del fundador o de la fundadora, mantener un cierto contacto.

En algunos casos el carisma, desde el principio, "agrupa" vocaciones de diversos estados de vida, personas de religiones diversas, etc. En otros, se da una apertura progresiva. Por ejemplo, un movimiento que inicialmente era para jóvenes, después se abre a personas más maduras; o un carisma religioso se extiende posteriormente a los laicos, hombres y mujeres, y luego a las familias. En algunos casos hay clérigos que sirven al movimiento con su ministerio (sin incardinarse necesariamente en él o en una entidad interna); en otros, en cambio, su presencia resulta meramente asociativa (socios que participan del carisma y se benefician de él).

La diversidad entre los movimientos es notable, por espiritualidad, carisma, organización, métodos, actividad y obras. Tan gran variedad hace extremadamente arduo identificar los elementos comunes a todos ellos. Sirven de ayuda aquí dos descripciones. La primera es de san Juan Pablo II y reza así: «una realidad eclesial concreta en la que participan principalmente laicos, un itinerario de fe y de testimonio cristiano que basa su método pedagógico en un carisma preciso otorgado a la persona del fundador en circunstancias y modos determinados» ${ }^{24}$. La segunda, de Ratzinger, es la siguiente: «generalmente los movimientos nacen de una persona, guía carismático, se configuran en comunidades concretas, que en virtud de su origen reviven el Evangelio en su totalidad y reconocen sin reticencias en la Iglesia su razón de ser, sin la cual no podrían subsistir» ${ }^{25}$. Los elementos comunes resultan ser la presencia de un fundador, de un carisma que lleva a vivir y testimoniar el Evangelio de un modo específico y la apertura a diversos tipos de fieles, si bien la mayoría son laicos.

${ }^{24}$ San Juan Pablo II, Mensaje a los participantes en el Congreso mundial de los movimientos eclesiales (Roma, 27-29 mayo 1998, n. 4 (https://w2.vatican.va/content/john-paul-ii/es/speeches/1998/ may/documents/hf_jp-ii_spe_19980527_movimenti.html).

25 «I movimenti nascono per lo più da una personalità carismatica guida, si configurano in comunità concrete che in forza della loro origine rivivono il Vangelo nella sua interezza e senza tentennamenti riconoscono nella Chiesa la loro origine di vita, senza di cui non potrebbero sussistere» (J. RATZINGER, I Movimenti ecclesiali e la loro collocazione teologica, cit., 47). La traducción es nuestra. 


\section{MOdO DE PROCEDER PARA LA CONFIGURACIÓN JURÍDICA}

¿Qué configuración jurídica dar a los movimientos eclesiales? Me parece que no existe una solución unívoca y preconcebida: hará falta siempre enfrentarse con la realidad de cada movimiento, con su carisma tal como se ha ido forjando y presentando en la vida, tal como ha ido arraigando en los fieles: en los hombres, en las mujeres, en los jóvenes, en los ancianos, en los clérigos, en los religiosos, en las familias, en los no católicos; y ver qué frutos concretos ha ido dando ${ }^{26}$. La metáfora más apropiada en la búsqueda de la configuración adecuada es la del proceso de elaboración de un traje a medida, de modo que se ajuste mejor a la persona que lo va a vestir. Como hace el sastre, se toman medidas: de los brazos, de las piernas, del pecho, del ancho, del largo... Después habrá que confeccionar el traje con la tela más conveniente, del color que mejor le vaya a la persona, a su edad, etc.

En nuestro caso, como se puede imaginar fácilmente, una tarea fundamental será incluir en un texto los elementos jurídicos que están presentes con mayor o menor intensidad en la vida del movimiento ${ }^{27}$. Las relaciones interpersonales que se dan al vivir un carisma tienen una dimensión de justicia, que se manifestará dentro del movimiento y también frente a los demás fieles y a la autoridad eclesiástica.

En una primera fase de toma de medidas se deben seguir dos criterios fundamentales: el respeto de las personas en cuanto tales y de sus posiciones eclesiales dentro del movimiento; y el respeto de la naturaleza del carisma.

a) Respeto de la persona y de sus posiciones eclesiales

Todo carisma verdaderamente eclesial debe respetar las exigencias de justicia propias de la naturaleza humana y de la vocación a la identificación con

${ }^{26}$ Es significativo que la ex. ap. Christifideles laici, para el discernimiento de los criterios de eclesialidad en las realidades agregativas, remite a los frutos: «Los criterios fundamentales que han sido enumerados, se comprueban en los frutos concretos que acompañan la vida y las obras de las diversas formas asociadas; como son el renovado gusto por la oración, la contemplación, la vida litúrgica y sacramental; el estímulo para que florezcan vocaciones al matrimonio cristiano, al sacerdocio ministerial y a la vida consagrada; la disponibilidad a participar en los programas y actividades de la Iglesia sea a nivel local, sea a nivel nacional o internacional; el empeño catequético y la capacidad pedagógica para formar a los cristianos; el impulsar a una presencia cristiana en los diversos ambientes de la vida social, y el crear y animar obras caritativas, culturales y espirituales; el espíritu de desprendimiento y de pobreza evangélica que lleva a desarrollar una generosa caridad para con todos; la conversión a la vida cristiana y el retorno a la comunión de los bautizados "alejados" ( (SAN JuAN PABLO II, Ex. ap. Christifideles laici, 30 diciembre 1988, n. 30).

27 Estos elementos se recogerán en los estatutos, constituciones y reglamentos del ente. 
Cristo dentro de la Iglesia. Lógicamente, no todos los aspectos que indico a continuación han de incorporarse a los estatutos, constituciones, reglas de vida y reglamentos. Pueden no ser explicitados, pero deben formar parte de la cultura jurídica del movimiento.

El respeto a la dignidad y a la libertad de todo fiel en el seguimiento de su propia vocación. Los derechos inviolables de la persona humana deben ser respetados y promovidos dentro de las nuevas realidades eclesiales. Toda vocación eclesial requiere una adhesión libre, voluntaria, tanto al inicio como durante las diversas etapas de la vida ${ }^{28}$. Seguir un carisma no suprime la libertad, también espiritual, de cada fiel, que tiene como guía constante al Espíritu Santo ${ }^{29}$. Esta libertad del fiel se expresa en algunos principios jurídicos tradicionales: libertad y no coerción en la elección del estado de vida, libertad en el acceso a los sacramentos y a las celebraciones litúrgicas, libertad en la elección del confesor, sin imponer jamás la obligación de confesarse con un superior ${ }^{30}$. Libertad en la dirección espiritual, respetando el derecho a la intimidad: nada de lo que se confía en el marco del acompañamiento espiritual puede ser revelado a otros o aparecer en informes sobre las personas sin el consentimiento previo de la persona interesada. El derecho a no ser sometido a presiones psicológicas, dependencia sexual, etc. El derecho a ser tratado como sujeto y no como objeto. Esto requiere una progresiva toma de conciencia, por parte del movimiento, de las cualidades personales de los individuos, como expresión de una maduración en la vida de éste. Todo miembro habrá de ser valorado, escuchado y consultado, sin ser considerado un permanente menor de edad.

Derecho a vivir de un modo digno de la condición bumana. Se ha de respetar y estar atentos a que las personas que siguen un carisma de modo totalizante

${ }^{28}$ Cfr. can. 219. Cfr. también A. D’AuRIA, Libertà del fedele e scelta della vocazione, Urbaniana University Press, Città del Vaticano 2012.

29 Cfr. Benedicto XVI, Homilía en la celebración de las primeras vísperas en la Vigilia de Pentecostés. Encuentro con los movimientos y nuevas comunidades eclesiales, 3 junio 2006, en la que indica que "los movimientos eclesiales quieren y deben ser escuelas de libertad, de esta libertad verdadera" (http://w2.vatican.va/content/benedict-xvi/es/homilies/2006/documents/hf_ben-xvi_hom_ 20060603_veglia-pentecoste.html).

30 Todo fiel es libre de confesar los pecados al confesor que elija (cfr. can. 991). El principio según el cual los superiores no deben escuchar las confesiones de sus súbditos es una norma de prudencia que protege la libertad de los fieles. Cfr. can. 985, aplicado a los maestros de novicios y al rector del seminario. La única excepción legítima se da cuando el súbdito pide espontáneamente al superior que le oiga en confesión. Cfr. can. $630 \$ 4$ para los religiosos. En el ámbito de la dirección espiritual se prevé que el superior no puede inducir al religioso a abrir su conciencia. Cfr. también can. $719 \$ \$ 3$ y 4 . Para los seminaristas, vid. cann. 240 y 246. 
puedan tener lo que sea conveniente y no sólo indispensable para su sostenimiento y vivienda, los cuidados médicos adecuados, la asistencia sanitaria incluido el acompañamiento psicológico, si fuese necesario ${ }^{31}$. En el caso de los jóvenes, es prudente que completen la formación profesional y académica emprendida antes de entrar en el movimiento, de modo que en el futuro tengan algunos títulos que les abran las puertas al mundo del trabajo. Por lo que se refiere a cuestiones de naturaleza económica, debe existir un sistema de trazabilidad de las aportaciones entregadas voluntariamente al movimiento, y de su empleo. Es recomendable que haya información periódica, accesible a los miembros, del estado económico del movimiento.

Se debe garantizar que al concluir su vida laboral el miembro del movimiento tenga la pensión adecuada o al menos la certeza de que alguien se hará cargo de él o ella. En caso de que una persona deba abandonar el movimiento, se debe garantizar que recibirá la ayuda necesaria, al menos en los primeros tiempos, para recomenzar una nueva vida ${ }^{32}$.

El respeto de la naturaleza de la familia y del matrimonio. Dentro del movimiento se deben respetar los espacios de autonomía y libertad necesarios para vivir la vocación conyugal y familiar. Los matrimonios deben ocupar espacios propios para vivir, separados de los demás, que les permitan vivir como pareja y como familia. Deben gozar de independencia económica: sobre la base de su trabajo tendrán un sueldo y una capacidad real de ahorro para los hijos. Además, se debe garantizar una autonomía de gobierno sobre la propia familia: los primeros educadores, también en la Iglesia, son los padres y son ellos los responsables del crecimiento humano y espiritual de sus hijos, sin delegaciones al movimiento ${ }^{33}$. Los padres son los responsables de la elección del co-

${ }^{31}$ El desarrollo de las sociedades en el siglo XX ha dado lugar a sistemas de asistencia social que garantizan un mínimo a todos los ciudadanos y a todo ser humano. Se trata de conquistas sociales fruto en muchos casos de la aplicación de la doctrina social de la Iglesia. Las contribuciones obligatorias al sistema sanitario nacional no son algo opcional para los ciudadanos ni, por tanto, para los miembros del movimiento. La legislación estatal en estas materias resulta vinculante y por eso debe ser conocida y cumplida. Los movimientos eclesiales están regulados por el derecho canónico, pero deben tener en cuenta las normas del derecho estatal, tanto en lo que se refiere a su reconocimiento, como en lo que se refiere al respeto de los derechos económicos, sociales y culturales de sus miembros. Cfr. ONU, Pacto internacional sobre los derechos económicos, sociales y culturales, 16 de diciembre de 1966.

32 Para la vida religiosa está previsto así. Cfr. can. 702.

${ }^{33}$ Cfr. cann. $226 \$ 2,774 \$ 2,835 \$ 4,867 \$ 1,914$. En estos cánones se recogen obligaciones de los padres en la educación humana y cristiana y su especial responsabilidad de favorecer la vida sacramental de los hijos. 
legio y escuela y son llamados a atender a las necesidades, también médicas, de sus hijos.

El respeto del ministerio ordenado como ministerio público al servicio del Pueblo de Dios. En todo movimiento en el que hay ministros sagrados entre sus miembros, sin caer en formas de clericalismo, se deben respetar las funciones propias del clero, al servicio del Pueblo de Dios, en particular en la predicación de la Palabra de Dios y en la administración de los sacramentos.

Cuando se den expresiones de vida consagrada en el movimiento, deberán respetarse sus elementos típicos, no sólo en la sustancia, sino también con modalidades operativas. Por ejemplo: tener espacios propios para la oración, para la vida común y vivienda separada para mujeres y hombres consagrados.

Estos elementos no son negociables y allí donde se han olvidado o pasado por alto ha habido numerosos problemas.

\section{b) Respeto de la naturaleza del carisma: secular o de vida consagrada}

Un primer elemento de discernimiento que oriente para una configuración jurídica consiste en determinar si el carisma que da lugar a un movimiento tiende hacia la vida consagrada o a la secular ${ }^{34}$. Si el carisma motor apunta hacia la vida consagrada mediante la profesión de los consejos evangélicos, parece que la solución más apropiada para la configuración jurídica del movimiento es explorar las formas típicas de la vida consagrada (institutos religiosos y seculares) o incluso la creación de una nueva forma de vida consagrada, de las que trata el c. 605. En cambio, en otros casos el carisma del movimiento está más conectado con la condición bautismal y secular de los fieles, sin modificar su estilo de vida. Un primer punto que hay que aclarar es cuál es la línea de fuerza del movimiento. La presencia de fieles que desean vivir los consejos evangélicos de pobreza, castidad y obediencia no es por sí misma determinante de la naturaleza del carisma. Habrá que examinar su origen, si nace dentro de un instituto religioso, si se inspira en un carisma religioso o si la presencia de algunas vocaciones de total donación a Dios es expresión de una verdadera consagración. La biografía del movimiento puede brindar elementos de reflexión en este campo. Cuando las cosas no estén demasiado claras se debería abrir entre los miembros un periodo de oración, estudio y reflexión so-

${ }^{34}$ Sobre este aspecto vid. L. NAVARRO, Aspectos canónicos de la consagración, cit., 824-826. 
bre la naturaleza del carisma, en un clima de discernimiento compartido. En este ámbito no caben imposiciones arbitrarias. No basta que en un movimiento algunos miembros vivan los consejos evangélicos para arrastrar a todos hacia la vida consagrada ${ }^{35}$. No es la práctica de los consejos, sino el carisma, lo que determina la naturaleza del movimiento.

\section{UN ÚNICO ENTE INTEGRADO POR LOS FIELES MIEMBROS \\ O UN ENTE COMPUESTO DE DIVERSOS ENTES}

Llegados a este punto en el intento contribuir a una configuración jurídica que se adecúe mejor al carisma, cabe examinar si éste da lugar a diversas realidades separadas entre sí, pero con algunos puntos de contacto. Si el desarrollo lleva a entes diversos con alguna vinculación, se debería diseñar un tipo de relación jurídica de conexión entre las diversas realidades. Cabría adoptar un modelo confederativo: diversos entes crean una unión entre ellos para algunos aspectos relativos al gobierno en materias comunes. La unión constituiría una confederación: diversos entes dotados de personalidad jurídica se unen, creando una nueva persona jurídica, sin que los entes federados sean absorbidos por la nueva persona. No se trata, por tanto, de una unión extintiva de las personas jurídicas ya existentes.

En cambio, si la unidad carismática constituye el elemento de fuerza de todo el conjunto, entonces se debe diseñar una configuración que refuerce la unidad del carisma, aunque haya habido que admitir algunos entes separados. Se debe subrayar la unidad carismática: más allá de la fórmula jurídica, lo que une es el carisma, el único carisma común. En la vida, lo que une no es el tra-

\footnotetext{
35 En los estatutos del Dicasterio para los laicos, la familia y la vida, se cita en el art. $7 \S 2$ un tipo de asociación que podría ponerse en relación con lo que acabo de indicar: las asociaciones de vida consagrada. No se dice qué son, pero se las coloca junto a las órdenes terceras seculares y se determina que el Dicasterio para los laicos es competente sólo en lo relativo a su actividad apostólica. Si se sigue la misma lógica del art. 111 de la const. ap. Pastor Bonus, la erección y la aprobación de estas asociaciones sería competencia de la Congregación para los Institutos de Vida Consagrada y Sociedades de Vida Apostólica. Ante ese artículo, Delgado se pregunta: «quali siano queste cosiddette "associazioni di vita consacrata" di cui il Dicastero curerebbe soltanto la loro attività apostolica. Sarebbero quelle erette con l'intento di divenire in futuro un istituto di vita consacrata o una società di vita apostolica? Oppure altre realtà aggregative laicali i cui membri, in tutto o in parte, assumono i consigli evangelici?» (M. DELGADO, Un nuovo dicastero..., cit., 713). No tenemos datos suficientes para dar respuesta adecuada pero, de haberla, debería estar vinculada al discernimiento sobre el carisma: de vida consagrada o de vida secular. En este último caso el carisma estaría más cercano de ser expresión de la condición bautismal y secular de los fieles, sin modificar su estilo de vida.
} 
je sino la persona. Todo lo dicho, dejando aparte de momento las limitaciones de las configuraciones jurídicas hasta ahora vigentes, nos lleva a sugerir una solución fuerte: poner de relieve que todos los miembros del movimiento están unidos por el carisma, que todos viven el carisma con la misma intensidad y todos son corresponsables de él. Desde el punto de vista jurídico se puede crear un ente global (una asociación privada de fieles: el contenedor eclesial más genérico y flexible) en el que todos los miembros del movimiento, en la distinción y complementariedad de sus vidas, están unidos como miembros del ente general, que se identifica con el movimiento mismo. El ente global es garante del carisma: para ser miembro de un ente sectorial se requiere serlo del ente general. Se trata de una condicio sine qua non. Si se pierde la condición de miembro de la asociación, se pierde también la condición de miembro del instituto religioso, de la sociedad de vida apostólica, y de la asociación clerical. Desde el punto de vista de estos entes en los cuales algunos miembros encuentran una configuración jurídica más específica (consagrados, clérigos), poner una condición para la admisión es un acto legítimo que nace de la conciencia de pertenecer al movimiento: quiero explícitamente que una persona que no sea del movimiento no pueda ser miembro del instituto religioso, de la asociación clerical, o de otro ente dentro del movimiento.

Esto se ha hecho recientemente en el Estatuto de la Asociación clerical de la Comunidad del Emmanuel, erigida por la Congregación para el Clero el 15 de agosto de 2017. En él se dispone que «los clérigos de la Comunidad del Emmanuel son clérigos seculares, comprometidos en la comunidad y "consagrados" en la Fraternidad de Jesús» ${ }^{36}$. Así pues, es condicio sin qua non, no sólo para el ingreso en la asociación clerical, sino para la permanencia en ella. Por eso se precisa que «cuando un miembro, sacerdote o diácono, de la Asociación clerical decide voluntariamente salir de la Comunidad del Emmanuel, pierde

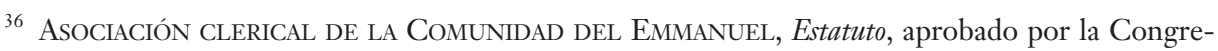
gación para el Clero el 15 de agosto de 2017, Premisa e). Cfr. también su art. 8. Para la Fraternidad de Jesús, cfr. COMUNIDAD DEL EMmanuEL, Estatuto, aprobado por el Dicastero para los Laicos, la Familia y la Vida el 15 de agosto de 2017, Premisa e-1), 2. Tanto el estatuto de esta Asociación clerical como el da la Comunidad del Emmanuel se encuentran en http://emmanuel.info/wp-content/uploads/2018/05/Statuts-2017_-espagnols.pdf. Otra asociación internacional de fieles prevé que algunos miembros lo son mediante la pertenencia a otra asociación. Es el caso de la Unión del Apostolado Católico. Los miembros de una sociedad de vida apostólica y de dos congregaciones pasan a ser miembros a iure de la Unión. Cfr. Statutes, art. 27, in http://www.unionedellapostolatocattolico.org/uploads/9/2/4/6/9246931/_2008-general-statutes-complete-english-text_1.pdf. 
de derecho la calidad de miembro de la Asociación clerical. Del mismo modo, si el clérigo decide voluntariamente salir de la Asociación clerical, pierde de derecho la calidad de miembro de la Comunidad. Esta separación pone fin a los derechos y a las obligaciones derivados de la calidad de miembro efectivo de la Asociación clerical y de la Comunidad $»^{37}$. Téngase presente que la $\ll$ Fraternidad de Jesús es depositaria de la vocación de la Comunidad del Emmanuel y de la fidelidad a su carisma ${ }^{38}$.

\section{MOVIMIENTOS, MINISTERIO SACRO E INCARDINACIÓN}

Quería tratar brevemente de algunos aspectos que se refieren a la incardinación en los movimientos ${ }^{39}$. Como es sabido, la incardinación no es simplemente tener clérigos en un movimiento. El instituto de la incardinación se refiere a algo más profundo: es una relación de naturaleza pastoral, con una dimensión jurídica que vincula al clérigo a un ente a cuyo servicio es destina-

37 ASOCIACIÓN CleRICAl DE LA COMUNIDAD DEL EMmanUEL, Estatuto, cit., art. 37.

${ }^{38}$ Cfr. ibid., Premisa d). Sobre el modo de unir diversos entes asociativos originados por el mismo carisma, escribí hace pocos años que «se la configurazione generale data al movimento è quella di associazione di fedeli, allora si dovrà esigere questo requisito fondamentale: qualsiasi membro di qualsiasi parte del movimento deve essere membro dell'associazione. Ciò significa che un membro di una società di vita apostolica o di un istituto religioso dovrà per forza essere membro dell'associazione più larga e sarà membro dell'istituto o società finché sia membro della citata associazione. Tale requisito dovrebbe essere indicato nelle Costituzioni o Statuti dell'ente di incardinazione e sarà anche accettato dal candidato a membro dell'istituto o società. Quanto riguarda il carisma e le attività comuni sarebbe governato dal movimento, mediante l'associazione comune. Quanto riguarda invece la vita e governo dell'istituto religioso o società sarà governato dai legittimi Superiori. Un'altra soluzione è stabilire una confederazione di enti che nel suo insieme costituisce il movimento. Il governo della confederazione deve garantire per tutte le parti la fedeltà e l'unità del carisma. Ciò comporta che nella composizione del governo centrale dovrebbero esserci rappresentanti dei diversi rami che compongono il movimento. Ogni parte o sezione accetta, nell'atto di chiedere di appartenere alla confederazione, che il governo centrale possa dare indicazioni e direttive riguardanti il carisma e anche orientamenti generali. Alla base della confederazione c'è la volontà libera di ogni parte (compresi anche Istituti di vita consacrata o Società di vita apostolica) di sottoporsi in tale parte al governo della confederazione. Logicamente queste due soluzioni richiedono una forte volontà di collaborazione fra le diverse parti della Confederazione e fra i diversi tipi di membri dell'associazione comune» (L. NAVARRO, Le forme associative nel codice di diritto canonico, en Esperienze associative nella Chiesa..., cit., 35-36, nota 42).

39 De ello me he ocupado en diversos momentos: L'incardinazione nei movimenti ecclesiali? Problemi e prospettive, en L. NAVARRo (a cura di), L'istituto dell'incardinazione. Natura e prospettive, Giuffrè, Milano 2006, 219-260, La incardinación de los clérigos de los nuevos movimientos asociativos, Ius Canonicum 48 (2008) 247-276; Clergy and New Ecclesial Movements, Studia Canonica 46 (2012) 375-400; «Incardinación», en DGDC, 4, 503-508. Vid. también F. COCCOPALMERIO, Il problema della incardinazione dei chierici nelle associazioni di fedeli, en Studi in onore di Carlo Gullo, I, Libreria Editrice Vaticana, Città del Vaticano 2017, 45-54. 
do y comporta la sujeción a un superior con potestad de jurisdicción. No todos los entes con clérigos en su interior gozan de la facultad de incardinar. Todos los entes jerárquicos la tienen, porque son realizaciones de la misión pastoral de la Iglesia en las que se manifiesta el carácter relacional del ministerio sacro, donde los sacerdotes y los diáconos son colaboradores necesarios del ministerio episcopal, cada uno a su modo. En cambio, entre los entes asociativos, tanto en el Derecho oriental como en el latino, no todos tienen la facultad de incardinar. Las asociaciones de fieles no gozan de esta facultad y las asociaciones clericales que la han recibido constituyen una excepción, un privilegio $^{40}$.

Independientemente de la naturaleza jerárquica o asociativa de los entes incardinantes, está claro que donde hay incardinación hay potestad de gobierno (potestad de jurisdicción), íntimamente ligada al ejercicio del ministerio (el superior gobierna al menos en parte el ministerio de los clérigos) al servicio de las almas.

¿Es necesaria una cura pastoral para los miembros del movimiento? La respuesta es, sin duda, afirmativa. ¿Cómo se debe satisfacer esta necesidad? Hay movimientos a los que puede bastar la presencia de capellanes o directores espirituales que desempeñan una parte de su ministerio en favor de los miembros del movimiento. Si esos capellanes pertenecen al movimiento y/o viven su carisma, eso los hace particularmente idóneos para ejercer un ministerio en el movimiento. Esos clérigos están incardinados en las diócesis o en otros entes y reciben de su superior el encargo de cuidar pastoralmente a los miembros del movimiento. En cuanto que son fieles pertenecientes a la diócesis, es responsabilidad del Obispo diocesano favorecer una adecuada cura pastoral y, en este caso, ésta debe ser congruente con el carisma del movimiento. El medio más simple a disposición del Obispo es confiar a algunos sacerdotes del movimiento el encargo de atender espiritualmente a esos fieles y colaborar en las actividades apostólicas del movimiento, mediante el ejercicio del ministerio sacerdotal.

Pero hay también movimientos cuya finalidad requiere el ejercicio del ministerio sagrado. Algunos movimientos, sin el ministerio sacerdotal ejercitado por

${ }^{40}$ En la Plenaria de la Congregación para el Clero de 2017 se presentó una Nota a proposito dell'incardinazione dei membri chierici in Associazioni Pubbliche Clericali en la que se indican cinco criterios para discernir la concesión de esta facultad a una asociación. Cfr. http://www.clerus.va/content/dam/clerus/Plenaria\%202017/01p\%20-\%20Incardinazione.pdf. 
algunos miembros, no estarían en condiciones de mantener vivo el carisma. En ciertos casos el movimiento puede exigir una total disponibilidad para el ejercicio del ministerio incluso en lugares lejanos, donde todavía no hay una implantatio Ecclesiae. Debe darse, por tanto, una vinculación entre carisma y ejercicio del ministerio.

Si el ministerio de un clérigo no está conectado con la finalidad y las características del ente asociativo, entonces no deberá haber incardinación en ese ente. Tal sería el caso si la presencia del clérigo en la asociación es algo puramente personal, sin que eso configure su modo de ejercer el ministerio. No sería lógico conceder la facultad de incardinar a un ente en el que el socio clérigo mantiene solamente relaciones de espiritualidad o de fraternidad, sin un ministerio vinculado al carisma.

Conceder la facultad de incardinar a un ente asociativo es manifestación de la madurez eclesial, porque se reconoce que, por una lado, está en condiciones de afrontar las obligaciones específicas que se asumen frente al clérigo (sustento y formación permanente) y que por otro, el ente se constituye en garante de la idoneidad del ministro sagrado (esto comporta también capacidad de discernimiento en el periodo de formación hacia el sacerdocio) y de la legitimidad de su ministerio.

Por eso, antes de atribuir la facultad de incardinar, la Iglesia se toma un tiempo prudencial para verificar la idoneidad y la madurez del ente ${ }^{41}$. Hasta que se conceda esa facultad, se hacen acuerdos entre las diócesis y los movimientos, en los que se tratan cuestiones relativas al ministerio de los clérigos, a su sustentación y a su disciplina.

Muy probablemente habrá un momento en que se podrá conceder la incardinación a los movimientos eclesiales (quizá directamente), pero siempre deberá hacerse caso por caso, tras un atento examen del carisma, de la madurez del movimiento, verificando su capacidad de discernimiento de la vocación sacerdotal, su capacidad de ocuparse de la sustentación del clero y de gobernar de modo adecuado el ministerio de los clérigos. Mientras tanto, el camino más seguro hacia la incardinación de los clérigos será la vía de las convenciones bien hechas, inspirándose al modelo delineado por el c. 271, en las que se tu-

${ }^{41}$ Tal madurez se manifiesta también en el número de vocaciones al sacerdocio. Es significativo que en el momento de la erección de la asociación clerical de la Comunidad del Emmanuel pertenecían a este movimiento 265 sacerdotes de 120 diócesis. Cfr. http://www.lavie.fr/religion/catholicisme/ce-que-le-changement-de-statut-des-pretres-de-l-emmanuel-veut-dire-29-08-201784481_16.php. 
telen los derechos y obligaciones de las personas implicadas (obispos, movimiento, clérigo), donde se fijen claramente las responsabilidades de cada uno.

De todo lo dicho resulta que, para conceder la facultad de incardinar, no es suficiente que haya vocaciones sacerdotales dentro del movimiento y que esos candidatos al sacerdocio sigan su espiritualidad.

\section{CONCLUSIÓN}

Nuestro cometido como juristas es precisamente hacer viable la vida de los dones carismáticos en el conjunto de la Iglesia, mediante una más profunda comprensión, que hará posible un mejor desarrollo y protección. El respeto de toda realidad carismática exige que ésta encuentre su inserción más satisfactoria en la Iglesia y a su servicio Por eso cada realidad debe ser tratada independientemente de las otras, en su identidad e irrepetibilidad. Habrá que confeccionar un traje a medida, sin copiar el de otros. Esto requiere tiempo, saber esperar, para examinar la praxis y cambiar lo que resulta poco conforme con el carisma y su evolución. Más que crear contenedores vacíos, tomados de otras experiencias, el criterio que debe guiar la redacción de las normas, de los estatutos o constituciones, reglamentos y directorios es que allí el carisma aparezca en sus elementos jurídicos, en su esplendor, respetando la naturaleza de la Iglesia. La sabiduría de la Iglesia consiste en saber ajustar progresivamente las configuraciones jurídicas a la naturaleza, praxis y vida de los carismas para que sean siempre en la Iglesia y de la Iglesia. Esto requiere una especial sensibilidad eclesial, tanto de los miembros de los movimientos como de la autoridad eclesiástica. Esto será posible si todos tenemos la mente y el corazón abiertos a estos dones del Espíritu a su Iglesia. 


\section{Bibliografía}

AA. Vv., Esperienze associative nella Chiesa. Aspetti canonistici, civili e fiscali, Libreria Editrice Vaticana, Città del Vaticano 2014.

Amos, J., Associations of the Christian Faithful in the 1983 Code of Canon Law: a canonical Analysis and Evaluation, Washington 1986.

Aymans, W., Kirchliche Vereinigungen, F. Schöningh, Paderborn 1988.

Baggio, S., Lettera del Card. Baggio a mons. Álvaro del Portillo 17 gennaio 1983, sulle prelature personali, Studia et Documenta 5 (2011) 379-380.

BeNEDICTO XVI, Homilía en la celebración de las primeras vísperas en la Vigilia de Pentecostés. Encuentro con los movimientos y nuevas comunidades eclesiales, 3 junio 2006.

-, Discurso en el encuentro con los párrocos y el clero de la diócesis de Roma, 22 febrero 2007.

BEYER, J., I movimenti ecclesiali, Vita consacrata 23 (1987) 143-156.

—, Il movimento ecclesiale: questioni attuali, Vita consacrata 26 (1990) 483-494.

COCCOPALmerio, F., Il problema della incardinazione dei chierici nelle associazioni di fedeli, en Studi in onore di Carlo Gullo, Libreria Editrice Vaticana, Città del Vaticano 2017, 45-54.

CONGRegación PARA El Clero, Nota a proposito dell'incardinazione dei membri chierici in Associazioni Pubbliche Clericali, Roma 2017.

Congreción para la Doctrina de la Fe, Carta Iuvenescit Ecclesia, 15 mayo 2016.

D'Auria, A., Le società di vita apostolica, en GRUPPo ITALIANO DoCEnTI DI DiritTo CANONICO (a cura di), La vita consacrata nella Chiesa, Glossa, Milano 2006, 169-194.

—, Libertà del fedele e scelta della vocazione, Urbaniana University Press, Città del Vaticano 2012.

De Fuenmayor, A. - Gómez Iglesias, V. - Illanes, J.L., El itinerario jurídico del Opus Dei: historia y defensa de un carisma, Eunsa, Pamplona 1989.

Delgado, M., Un nuovo dicastero per i fedeli laici, la famiglia e la vita, Ius Ecclesiae 28 (2016) 700-715.

De Paolis, V. - Mosca, V., La vita consacrata nella Chiesa, Marcianum Press, Venezia 2010.

FELICIANI, G., La partecipazione di altri credenti alla vita delle associazioni cattoliche, en PONTIFICIUM CONSILIUM PRO LAICIS, Ecumenismo e dialogo interreligioso: il contributo dei fedeli laici, Città del Vaticano 2002, 163-168. 
FRANCISCO, Estatuto del Dicasterio para los Laicos, la Familia y la Vida, 10 de abril de 2018.

Fuentes, J. A. (ed.), Las asociaciones de fieles. Aspectos canónicos y civiles, Eunsa, Pamplona 2011.

GANCI, A., La questione della consacrazione dei fedeli nei Movimenti Ecclesiali. Stato attuale e prospettive future, Roma 2018.

GHIRLANDA, G., Questioni irrisolte sulle associazioni dei fedeli, Ephemerides Iuris canonici 49 (1993) 73-102.

Gruppo Italiano Docenti di Diritto Canonico (a cura di), Fedeli, associazioni, movimenti, Glossa, Milano 2002, 127-265.

Illanes, J. L., Nota alla Lettera del Card. Baggio a mons. Álvaro del Portillo 17 gennaio 1983, sulle prelature personali, Studia et Documenta 5 (2011) 369-378.

Juan Pablo II, Const. ap. Ut sit, 28 noviembre 1982.

—, Const. ap. Pastor Bonus, 28 junio 1988.

—, Ex ap. Christifideles laici, 30 diciembre 1988.

—, Ex. ap. Vita Consecrata, 25 marzo 1996.

-, Mensaje a los participantes en el Congreso mundial de los movimientos eclesiales, Roma, 27-29 mayo 1998.

Marano, V., Il fenomeno associativo nell'ordinamento ecclesiale, Giuffrè, Milano 2003.

Martínez Sistach, Ll., Las asociaciones de fieles, Thomson Reuters Aranzadi, Cizur Menor (Navarra) 2016.

Navarro, L., Diritto di associazione e associazioni di fedeli, Giuffrè, Milano 1991.

—, Sub c. 302, en Comentario exegético al Código de Derecho Canónico, II, Eunsa, Pamplona 2002, 443-445.

-, Canonical dimensions of the new charisms and ecclesial movements, Philippine Canonical Forum 4 (2002) 37-74.

-, L'incardinazione nei movimenti ecclesiali? Problemi e prospettive, en L. NAVARRO (a cura di), L'istituto dell'incardinazione. Natura e prospettive, Giuffrè, Milano 2006, 219-260.

—, La incardinación de los clérigos de los nuevos movimientos asociativos, Ius Canonicum 48 (2008) 247-276.

-, Aspectos canónicos de la consagración, en M. BlanCO - B. Castillo J. A. Fuentes - M. SÁNChez Lasheras (coords.), Ius et iura. Escritos de Derecho Eclesiástico y de Derecho Canónico en honor del profesor Juan Fornés, Comares, Granada 2010, 807-828. 
—, Clergy and New Ecclesial Movements, Studia Canonica 46 (2012) 375-400.

—, «Asociación de fieles», en J. Otaduy - A. Viana - J. SEDANo (eds.), Diccionario General de Derecho Canónico, I, Thomson Reuters Aranzadi, Cizur Menor (Navarra) 2012, 524-525 (en adelante, DGDC).

—, «Incardinación», en DGDC, 4, 503-508.

ONU, Patto internazionale sui diritti economici, sociali e culturali, 16 dicembre 1966.

Ratzinger, J., I Movimenti ecclesiali e la loro collocazione teologica, en PONTIFICiUm Consilium pro Laicis, I movimenti nella Chiesa. Atti del Congresso mondiale dei movimenti ecclesiali, Roma, 27-29 maggio 1998, Libreria Editrice Vaticana, Città del Vaticano 1999.

—, Dialogo con il cardinale foseph Ratzinger, en PONTIFICIUM CONSILIUM PRO LAICIS, I movimenti ecclesiali nella sollecitudine pastorale dei vescovi, Libreria Editrice Vaticana, Città del Vaticano 2000, 228-229.

RinCón-PÉREZ, T., La vida consagrada en la Iglesia latina: estatuto teológicocanónico, Eunsa, Pamplona 2001.

RiveTti, G., Il fenomeno associativo nell'ordinamento della Chiesa tra libertà e autorità, Giuffrè, Milano 2008.

RodrígueZ-OcaÑa, R., Las asociaciones de clérigos en la Iglesia, Eunsa, Pamplona 1989.

Schulz, W., Der neue Codex und die kirchliche Vereine, Bonifatius, Paderborn 1986.

STANKIEWICZ, A., Le prelature personali e i fenomeni associativi, en S. GHERRO (a cura di), Le prelature personali nella normativa e nella vita della Chiesa, Venezia-Scuola Grande di San Rocco, 25 e 26 giugno 2001, CEDAM, Padova 2002, 137-163. 